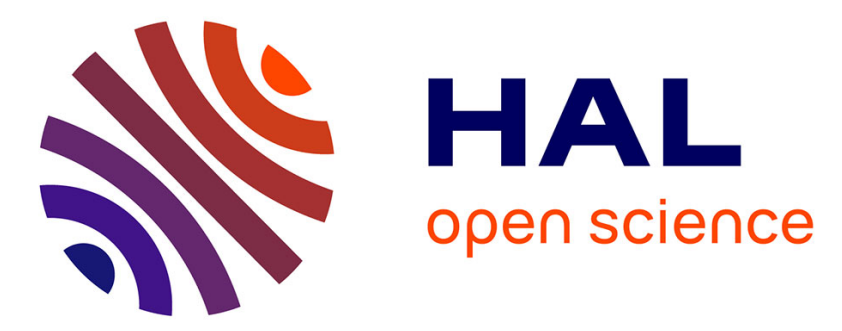

\title{
Is Ranibizumab effective in stopping the loss of vision for Choroidal Neovascularization in Pathologic Myopia? A Long Term Follow-up Study
}

Maria Vadalà, Alfredo Pece, Stefano Cipolla, Carla Monteleone, Giuseppe Fasolino, Alessandra Casuccio, Salvatore Cillino

\section{To cite this version:}

Maria Vadalà, Alfredo Pece, Stefano Cipolla, Carla Monteleone, Giuseppe Fasolino, et al.. Is Ranibizumab effective in stopping the loss of vision for Choroidal Neovascularization in Pathologic Myopia? A Long Term Follow-up Study. British Journal of Ophthalmology, 2010, 95 (5), pp.657. 10.1136/bjo.2009.174243 . hal-00588346

\section{HAL Id: hal-00588346 https://hal.science/hal-00588346}

Submitted on 23 Apr 2011

HAL is a multi-disciplinary open access archive for the deposit and dissemination of scientific research documents, whether they are published or not. The documents may come from teaching and research institutions in France or abroad, or from public or private research centers.
L'archive ouverte pluridisciplinaire HAL, est destinée au dépôt et à la diffusion de documents scientifiques de niveau recherche, publiés ou non, émanant des établissements d'enseignement et de recherche français ou étrangers, des laboratoires publics ou privés. 


\title{
Is Ranibizumab effective in stopping the loss of
}

\author{
vision for Choroidal Neovascularization in
}

\section{Pathologic Myopia? A Long Term Follow-up}

\section{Study}

D BJOPHTHALMOL/2009/174243.

Maria Vadalà, MD, PhD, Alfredo Pece $\$, M D$, Stefano Cipolla, MD, Carla Monteleone, MD, Giuseppe Fasolino ^, MD, Alessandra Casuccio BS, Salvatore Cillino, MD, PhD, . Dipartimento di Neuroscienze Cliniche, Sezione di Oftalmologia, Università di Palermo, †Unità operativa di Oftalmologia, Ospedale di Melegnano, via Pandina, Melegnano (MI), Fondazione RETINA 3000, Milano

^ Unità operativa di Oculistica, Casa di Cura Villa Tiberia, Roma

Corresponding author:

Maria Vadalà, Dipartimento di Neuroscienze Cliniche, Sezione di Oftalmologia, Università di Palermo, via L. Giuffrè 13, 90127 Palermo, tel +390916553934, fax +390916553930 , email maria.vadala@unipa.it

Key words: pathological myopia, choroidal neovascularizaton, ranibizumab, intraocular injection, anti-VEGF drugs. 


\section{ABSTRACT}

Purpose: To assess the efficacy and safety of Ranibizumab in the treatment of choroidal neovascularization (CNV) caused by pathologic myopia (PM).

Design: Prospective, multicenter, interventional case series.

Methods: 40 of 39 consecutive patients with PM and CNV were treated with "on-demand" intravitreal injection of ranibizumab $0.5 \mathrm{mg}$. Final best-corrected VA (BCVA) and its change from baseline were the main outcome measures. Changes in Optical Coherence Tomography (OCT) central retinal thickness (CRT) were a secondary outcome.

Results: Mean age was $53 \pm 13$ years, mean refractive error $-13.5 \pm 6.5$ diopters. Median follow-up was $13.3 \pm 2$ months (range $12-18$ ). Fifteen eyes $(37.5 \%)$ had previously been treated with photodynamic therapy (PDT). The mean baseline logMAR BCVA (ETDRS vision chart) was $0.68 \pm 0.34$ (Snellen equivalent 20/131) and $21 \pm 16$ letters. The final mean logMAR BCVA was $0.27 \pm 0.2$ ( $p$ 0.008) (20/42) and $40.5 \pm 14$ letters ( $p$ 0.01). Mean final VA improved in $82.5 \%$ of patients, in $60 \%$ by 3 or more lines,(median number of lines gained 2.9). Even six out of seven cases of low vision $(\leq 1.1$ LogMAR) at the final examination improved vision. Mean OCT CRT reduced from $218 \pm 70$ $\mu \mathrm{m}$ to $175 \pm 46 \mu \mathrm{m}$ ( $\mathrm{p} 0.02)$. Age and previous PDT did not influence results $(\mathrm{p}, 0,05)$. The mean number of injection was $2.8 \pm 1.2$ (range 1-6). No ocular or systemic side effects were observed.

Conclusion: Ranibizumab was an effective treatment for stabilizing and improving vision in $92.5 \%$ of myopic CNV in a long term follow-up with a low number of injections. 


\section{INTRODUCTION}

Choroidal neovascularization (CNV) is the main cause of acute vision loss in pathologic myopia (PM).[1-2]. The natural course of the disease accounts for low visual acuity (20/200) in $44-60 \%$ of the patients after 24 months. Laser photocoagulation is no longer used in juxtafoveal CNV, because of large retinal scars increasing over time.[3] Photodynamic therapy (PDT) with verteporfin may stabilize visual acuity (VA) and significantly reduce visual loss in eyes with subfoveal and juxtafoveal CNV PM.[4-6] Nevertheless the results show a decrease of VA in up to $1 / 3$ of the eyes with subfoveal CNV and only $6 \%$ of the eyes gain more than 3 lines in juxtafoveal form.[6] Meanwhile, the widespread use of anti-VEGF drugs in the treatment of CNV due to age-related macular degeneration (AMD) has opened new therapeutical strategies.

Bevacizumab off-label use in CNV related to PM has been evaluated in a few clinical nonrandomized clinical trials with a follow-up period of maximum 12 months follow-up.[7-8] Few reports about ranibizumab show short-term efficacy in maintaining vision.[9-12] We report the results of a 12-month prospective study in patients with pathologic myopia who were treated with intravitreally administered ranibizumab $0.5 \mathrm{mg}$ for CNV.

\section{MATERIALS AND METHODS}

Forty eyes of 39 patients with CNV related to pathologic myopia were consecutively enrolled in this open-label, multicenter, non-randomized, prospective case series. They were treated with an off-label intravitreal administration of ranibizumab $0.5 \mathrm{mg}$, regardless of lesion location.

Inclusion criteria were: 1) highly myopic eyes, spherical equivalent greater than -6 diopters (D), 2) posterior pole myopic retinal changes (lacquer cracks, chorioretinal atrophy, papillary crescent, posterior staphyloma), 3) fluorescein angiography (FA) detection of the subfoveal or iuxtafoveal CNV , 4) best-corrected visual acuity $>20 / 400$ at baseline, 5) 
duration of symptoms no longer than 4 weeks before enrollment, 6) minimum follow up of 12 months, 7) clear ocular media.

Exclusion criteria included: 1) post inflammatory macular changes, 2) extrafoveal CNV, 3) age-related macular alterations, 4) refractive media opacities, 5) presence of other maculopathies as diabetic retinopathy or retinal vascular occlusion, 6) history of recent myocardial infarction or other thromboembolic events, 7) other previous intravitreal drugs injections, 8) ocular hypertension or glaucoma.

Previous photodynamic therapy was not considered as an exclusion criteria if administered more than three months before enrolling. However no additional PDT session was performed during the follow-up and treatment options included either "on demand" ranibizumab intravitreal injections or observation.

Best corrected visual acuity (BCVA) was recorded using the Early Treatment Diabetic Retinopathy Study (ETDRS) chart at 4 meters distance using a logMAR scale: results were recorded as logMAR values and the number of letters read. At the baseline and at every examination, all patients underwent the standard ocular examination with ETDRS VA evaluation, biomicroscopy, tonometry, and OCT evaluation (Stratus OCT 4.01, Carl Zeiss Meditec, Inc.,Dublin, CA,USA). Retinal fluorescein angiography (TRC-50/IMAGEnet H 1024 system, TOPCON, Tokio. Japan, and/or Heidelberg Retina Angiograph 2, Heidelberg Engineering, Heidelberg, Germany) was performed at baseline within the 15 days prior to the initial visit, and subsequently, according to the judgment of the ophthalmologist, during the follow-up period.

The Retinal Thickness Map analysis program was applied with the extrapolation of data from six diagonal six-mm radial line scans. The scans were reviewed and manually caliper-assisted measurements were used in case of delineation errors. Standard deviation bigger than $10 \%$ of the macular thickness was considered out of range and 
scans were repeated or rejected. A decrease of $10 \%$ thickness in comparison with the baseline was considered as a reduction, while an increase of $10 \%$ as an amount.

The off label use of the drug and its potential risks and benefits were discussed extensively with all the patients and written informed consent was obtained. The study was conducted in accordance with the tenets of the Declaration of Helsinki.

Patients received an initial dose of $0.5 \mathrm{mg}(0.05 \mathrm{ml})$ of ranibizumab using the standard injection procedure in a surgical room.[13] Patients were reexamined the day after treatment. All patients were given detailed instructions and asked to call promptly if any significant changes in vision occurred. The patients were examined on a monthly basis, after the injection for the first three months, and monthly or quarterly thereafter, according to the judgement of the specialist.

Re-treatment was performed if any of the following conditions occurred: decrease of BCVA and/or increase of metamorphopsia, new retinal hemorrhage, increase of retinal/subretinal fluid or retinal thickness on OCT, CNV leakage on FA images.

The primary outcome was considered to be the improvement of visual acuity with a minimum of 5 letters (one ETDRS line), or the stabilization of VA. Secondary outcome was the changes in OCT central retinal thickness. Alfa level (p) was fixed at 0.05 , as a probability of $95 \%$. Statistical analysis was performed by means of a non-parametric Wilcoxon signed-ranks test and two-tailed t test, provided by SAS (Statistical Analysis Software) for Windows 8.0 (Microsoft Corp. USA), in order to evaluate BCVA and OCT central retinal thickness changes. The influence of age, previous PDT and lesion size on VA changes was analyzed by means of multivariate linear regression.

Visual acuity changes from baseline ware defined as improved if an increase of 1 ETDRS line or five letters was registered, or worsened if there was a decrease of 1 line; otherwise VA was considered unchanged,

Data are presented as mean, standard deviation (SD), median, and percentage (\%). 


\section{RESULTS}

Thirty-nine patients were enrolled in this study and forty eyes were treated. Twelve patients were men and twenty-seven were women; mean age at the initial examination was 53 years old (SD 13, range 32-80 years). Mean refractive error was - 13.5 D (SD 6.5 D, range -6 to $-28 \mathrm{D})$. In twenty-nine eyes the CNV was subfoveal $(72.5 \%)$ and in eleven eyes it was juxtafoveal (27.5\%). Fifteen eyes (37.5\%) were previously treated with PDT, twenty-three (57.5\%) were not. The mean ETDRS BCVA at baseline was 0.67 logMAR (SD 0.34, range 1.1-0.1, Snellen equivalent 20/131), and 21 letters (SD 16, range 0-50). The mean follow-up was 13.3 months (SD 2, range 12-18 months). All the patients completed a12-month follow-up, nine of them being followed-up for 18 months. Clinical data at baseline are reported in table 1. 
Table 1: baseline characteristics of patients at the study entry

\begin{tabular}{l|l} 
Findings & \multicolumn{1}{l}{ Values } \\
\hline N.of eyes (patients) & $50(39)$ \\
Mean age ( \pm SD) (years) & $-13.5( \pm 6.5)$ \\
Mean refractive error ( \pm SD) (diopter) & $29(72.5)$ vs 11 \\
N. subfoveal CNV vs juxtafoveal (\%) & $(27.5)$ \\
Mean follow-up ( \pm SD) (months) & $13.3( \pm 2)$ \\
N. previously PDT treated & $15 / 40$ \\
N. PDT naive & $23 / 40$ \\
Mean LogMAR BCVA ( \pm SD) & $0.67( \pm 0.34)$ \\
Mean letter BCVA ( \pm SD) & $21( \pm 16)$ \\
Mean OCT CRT* $( \pm$ SD) (microns) & $218.9( \pm 70)$ \\
\hline
\end{tabular}

*central retinal thickness measured by optical coherence tomography.

Post-treatment visual outcomes are displayed in table 2.

Table 2: outcomes at the end of the follow-up

\begin{tabular}{|c|c|c|c|}
\hline Findings & Values & $p$ values $\S$ & \\
\hline Mean LogMAR BCVA $\pm S D$ & $0.27( \pm 0.2)$ & 0.008 & \\
\hline Mean letter BCVA $\pm S D$ & $40.5( \pm 14)$ & 0.01 & \\
\hline $\begin{array}{l}\text { Improvement (gain } \geq 1 \text { line) ( } \mathrm{n} \text {. } \\
\text { eyes (\%)) }\end{array}$ & $32 / 40(80)$ & & $\begin{array}{l}=1 \text { line } 9 / 32(28) \\
=2 \text { lines } 4 / 32(12.5)\end{array}$ \\
\hline Stability (n. eyes (\%)) & $5 / 40(12.5)$ & & $\geq 3$ lines 19/32 (59.5) \\
\hline $\begin{array}{l}\text { Worsening (loss } \leq 1 \text { line) } \\
\text { (n. eyes (\%)) }\end{array}$ & $3 / 40(7.5)$ & & \\
\hline Mean OCT CRT ( \pm SD) (microns) & $175( \pm 46)$ & 0.02 & \\
\hline Mean $n$. injections $( \pm S D)$ & $2.8( \pm 1.2)$ & & \\
\hline
\end{tabular}

$\S p$ values when comparing with values at the baseline 
The mean BCVA was stable or improved during post-treatment follow-up with a mean final VA of 0.27 logMAR (SD 0.2, range 1.1-0.0, Snellen equivalent 20/41) and 40.5 letters (SD 14 , range $0-55)$ at 12 months after enrolling ( $p=0.008$ for LogMAR, 0.01 for letters) (Figure 1).

The final BCVA, compared with baseline, improved in 32 out of 40 eyes $(80 \%)$, decreased in 3 eyes $(7.5 \%)$, and remained stable in 5 eyes (12.5\%). In the eyes showing improvement, the median number of lines gained from baseline was 2.9 (range 1-8), and 19 out of the 32 (59.4\%) patients improved by three or more lines: nine eyes $(28 \%)$ improved by one line, 4 eyes (12.5\%) by 2 lines. Three eyes worsened in visual acuity despite therapy: one eye lost one ETDRS line, one eye two lines and the third case lost three lines. They however maintained BCVA between 0.2 and 0.6 LogMAR. Seven eyes had BCVA lower than 1 LogMAR (range 1.1-1.5) at the enrolling time but, at the end of the follow-up period, only one eye was lower (1.5 LogMAR): that was its exact BCVA at the start-up, so it was considered as stabilized.

Mean central macular thickness analyzed by OCT showed a reduction in all the cases, from 218.9 (SD 70) microns to 175 (SD 46) microns $(p=0.02)$ (Figure 2).

When analyzing visual acuity results in relation to refractive errors, age and lesion size, no statistical accordance was found. Eyes with an initially poor VA (lower than 1.1 LogMAR) did not statistically differ in visual improvement from those with initially good VA.

Considering the entire group, the mean number of injections was 2.8 (SD 1.2): the number of treatments varied from 1 to a maximun of 6 .

The eyes previously treated with PDT were compared with the naïve ones. No statistical accordance was found ( $p>0.05$ ) regarding age, refractive errors, lesion size, BCVA, central macular thickness and the response to a ranibizumab injection. Also the mean 
number of injections (2.56 vs 2.6) was unremarkably different. The mean number of letters gained was 31 vs 34 (p 0.2).

No ocular or systemic side effects were observed: particularly, neither retinal treas nor detachment occurred during the observation.

Figure 3 shows fluorescein angiography and OCT changes from basal observation to the last examination.

\section{DISCUSSION}

Treatment of CNV in PM is still in debate and should be further defined. Currently laser photocoagulation is the standard treatment for extrafoveal CNV [14], while PDT is the only approved therapy for subfoveal lesions showing significant visual and anatomic benefits [4-6]. However two- and three -year observational reports [15-16] fail to demonstrate the effectiveness of PDT in stabilizing vision or reducing severe loss of vision versus a placebo. Moreover, in juxtafoveal form, about $25 \%$ of eyes had experience of a decrease in vision and only $6 \%$ of the eyes gained 3 or more lines.[6]

Vascular endothelial growth factor A (VEGF-A) has been implicated as a major mediator responsible for subretinal neovascularization in several ocular diseases and it is now the main target for therapy in exudative age-related macular degeneration. Ranibizumab and bevacizumab are the most diffused anti-VEGF drugs for AMD complicated by CNV, giving a pan-vascular endothelial growth factor blocking.[17-19] The effect of anti-VEGFdrugs on aqueous VEGF and PEDF levels on other forms of CNV, as in PM, has been demonstrated [20], and such therapy is now having wide clinical support.[21] Previous papers about bevacizumab in myopic CNV indicate very promising results.[7-8] Ikuno et coll. [7], in a retrospective analysis, enrolled 63 myopic eyes and treated them "on demand", disregarding about CNV clinical form, visual acuity or timing of symptoms at the enrolment. The mean number of injections was $2.4 \pm 1.4: 40 \%$ of patients had improved 
vision ( $27 \%$ from three to six lines, $13 \%$ six or more lines), while $56 \%$ remained stable, with a gain or loss of less than three lines. Three patients (5\%) lost more than three lines in twelve months, because of enlargement of macular atrophy.

Gharbiya et coll. [8], in a one-year follow-up prospective study on 20 eyes, demonstrated that $1.25 \mathrm{mg}$ intravitreal bevacizumab can improve vision significantly and, reduce macular thickness at the OCT and angiographic leakage in $95 \%$ of cases. In $90 \%$ of subjects vision improved by 10 or more letters and in $70 \%$ by 15 or more letters. None of the patients experienced a worsening of visual acuity with respect to the baseline condition. The mean number of injections was 4 , ranging from 3 to 7 , starting with a loading dose. Very few papers report clinical experience with ranibizumab.[9-12] Explanations could be that PDT has been stated as in-label treatment and the different costs between anti-VEGF drugs.

Silva et coll. [9] retrospectively evaluated the efficacy of ranibizumab in myopic CNV in 26 eyes followed up for three -six months, while Kostantidinis et al. [10] prospectively enrolled 14 eyes and followed them for up to an average of 8 months (range 3-16 months). They showed a positive trend in vision recovery, stable vision after the third month and a slower reduction in OCT macular thickness.

Monés [11] prospectively enrolled 23 patients with CNV related to PM, treated "on demand". Almost $70 \%$ of patients gained al least 1 line of visual acuity in a one-year follow-up, with a mean number of injections equal to 1.5. Intravitreal ranibizumab has also been suggested as first line treatment in 16 patients by Lai et al. [12], who chose the loading dose as protocol: they observed a gain in vision in $75 \%$ of patients and only one patient needed retreatment during the follow-up of 12 months.

In our paper we confirm the efficacy of intravitreal injection in myopic CNV. The final mean VA improved in 32 out of the 40 eyes considered and was stable in five (92.5\%). The median number of lines gained was 2.9 from the baseline. About $60 \%$ of all patients 
improved by 3 or more lines. Ranibizumab stabilized BCVA to the range of legal blindness in one eye only, while it allowed six eyes to recover to mild low vision level (range 1-0.5 LogMAR). Even in those cases where BCVA worsened, it stabilized between 0.6 and 0.2 LogMAR.

We did not notice any difference in visual outcome between treated eyes previously treated with PDT and naïve eyes. Mechanisms of action of PDT and ranibizumab are different, and therefore where PDT is unsuccessful, anti-VEGF blocking is always a treatment opportunity. The role of PDT in promoting fibrosis should however be considered [22] in evaluating visual prognosis.

Which is the most effective regimen to adopt in non-AMD CNV still remains uncertain. Clinically myopic CNV differs from AMD-CNV, the former being slower in natural evolution with a variable visual outcome.[2] The role of pigment epithelium (RPE) and the release of different VEGF-related factors, is probably the key to the differences.[23] Patients are often young and therapies can be more effective because of the health RPE that is able to react adequately, creating a barrier to the CNV development. The same results were observed after PDT treatments in the past.[5-6, 24]

For these reasons we think that, in myopic CNV, the "on demand" regimen may be preferable with respect to the loading phase; this would lead to a lower number of injections, lower risks and less expenses. By now we don't have any controlled trial assessing the best modality of treatment in myopic CNV, however, among the papers published, some indicate very good results with the on demand regimen, the final mean number of injection being very low. In our paper we observed a mean number of injections of 2.8 in the first year, indicating a better prognosis in myopic CNV than in AMD (5.6 reported in PrONTO study).[25] In our series, the number of treatments were not related to poorer final visual acuity, in contrast with other reports about bevacizumab.[8] 
Even though, in our series, OCT central foveal thickness shows statistically significant

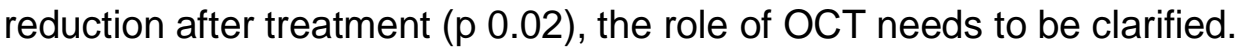

In myopic patients OCT may be considered useful to better define the diagnosis of CNV, excluding the presence of vitreoschisis with foveal alterations, tractions, and small macular holes. However, since PM-CNV can often have minimal leakage and choroid is usually very thin, OCT macular thickness can be irrelevant and the presence of fluid very scarce (see fig. 2 case 1). Furthermore the Stratus OCT may give us a lot of artifacts and would therefore need a very skilled examiner.

New spectral domain OCTs will give us more and better clinical information, but at the present moment, considering also that Stratus OCT is the gold standard in current scientific reports, in our opinion we should be very careful in carrying out a treatment or a retreatment of patients on the basis of OCT only. In our experience metamorphopsia is the leading symptom and should be highly considered in reaching a decision.

Several reports underline that refractive error, lesion dimension and age can influence treatment response, both for PDT and for anti-VEGF drugs.[5, 8, 24] However in our cohort of patients, statistical analysis did not show any correlation with age, refractive error or previous PDT. This issue surely deserves more investigation.

The safety of the drug was confirmed by our report. None of the patients developed any ocular or systemic side effects associated with intravitreal ranibizumab.

Efficacy and safety of a new drug should be tested on a large population as it happened in AMD trials; this seldom happened for myopic population. When evaluating literature about myopic CNV and anti-VEGF drugs, our series is large and can be accepted as representative of this population. We hope larger multicenter trial will offer stronger support to clinical practice. Further limitation of our paper is follow-up extension: we agree that clinical trial or observational studies should have at least 12 months of follow-up or 24-36 months in order to really compare results with natural history. The study lacks of a control 
group: however, nowdays we consider ethically unacceptable to perform comparison with randomized untreated patients, since therapies really changed prognosis of the disease.

\section{CONCLUSION}

International trials with ranibizumab negated any subgrouping of CNV and therefore treatment with anti-VEGF drugs is equally suggested for any form or localization of CNV in AMD. Anti-VEGF drugs give a high chance of stabilizing and improving vision that has otherwise deteriorated because of CNV. These drugs are therefore currently used in any form of CNV, also in off-label settings.[21] In our experience, intravitreal injection of ranibizumab appears to be very effective in the treatment of myopic CNV, with a high proportion of patients reporting an improvement in vision and a mean of 3 injections in the first year. Treatment is also able to avoid legal blindness. The correct regimen of treatment, as well as retinal and choroidal changes with the time, still need to be defined

\section{ACKNOWLEDGEMENTS}

To Giuseppe Bianco, clever help in managing surgical times.

\section{REFERENCES}

1. Yoshida T, Ohno-Matsui K, Yasuzumi K, et al. Myopic choroidal neovascularization.Ophthalmology 2003; 110(7):1297-305.

2. Soubrane, G. Choroiodal Neovascularization in pathologic myopia: recent developments in diagnosis and treatment. Survey Ophthalmol 2008;53(2):121-38.

3. Brancato R, Pece A, Avanza P, et al. Photocoagulation scar expansion after laser theraphy for choroidal neovascularization in degenerative myopia. Retina 1990;10(4): 239-43. 
4. Verteporfin in Photodynamic Therapy Study Group. Photodynamic therapy of subfoveal choroidal neovascularisation in pathologic myopia with verteporfin. 1-year results of a randomized clinical trial-Vip report $N^{\circ} 1$. Ophthalmology 2001;108:84152.

5. Pece A, Isola V, Vadalà $M$, et al. Photodynamic Therapy With Verteporfin for subfoveal Choroidal Neovascularizzation secondary to Pathologic Myopia: A Longterm Study. Retina 2006;26 (7): 746-51.

6. Pece $A$, Vadalà $M$, Isola $V$, et al. Photodynamic Therapy With Verteporfin for Juxtafoveal Choroidal Neovascularizzation in Pathologic Myopia: A Long-term Follow-up Study. Am J Ophthalmol 2007;143:449-54.

7. Ikuno $\mathrm{Y}$, Sayanagi $\mathrm{K}$, Soga $\mathrm{K}$, et al. Intravitreal bevacizumab for choroidal neovascularization attributable to pathological myopia: one-year results. Am J Ophthalmol 2009;147:94-100.

8. Gharbiya M, Allievi F, Mazzeo L, et al. Intravitreal bevacizumab treatment for choroidal neovascularization in pathologic myopia: 12-month results. Am J Ophthalmol 2009;147:84-93.

9. Silva RM, Ruiz-Moreno JM, Nascimento J, et al. Short-term efficacy of intravitreal ranibizumab for myopic choroidal neovascularization. Retina 2008;28(8):1117-23.

10. Kostantidinis L, Mantel I, Pournaras JAC, et al. Intravitreal ranibizumab (Lucentis) for the treatment of myopic choroidal neovascularization. Graefes Arch Clin Exp Ophthalmol. 2009;247:311-8.

11. Mones JM, Amselm L, Serrano A, et al. Intravitreal ranibizumab for choroidal neovascularization secondary to pathologic myopia: 12-month results. Eye 2009;23(6):1275-80. 
12. Lai TY, Chan WM, Liu DT, et al. Intravitreal ranibizumab for the primary treatment of choroidal neovascularization secondary to pathologic myopia. Retina 2009;29(6):750-6.

13. Aiello LP, Brucker AJ, Chang S, et al. Evolving guidelines for intravitreous injections. Retina 2004; 24:S3-S19.

14. Secretan M, Kuhn D, Soubrane G, et al. Long-term visual outcome of choroidal neovascularization in pathologic myopia. Natural history and laser treatment. Eur $\mathrm{J}$ Ophthalmol 1997;7:307-16.

15. Krebs I, Binder S, Stolba U, et al. Choroidal neovascularization in pathologic myopia: three-year result after photodynamic therapy. Am J Ophthalmol 2005; 140: 416-25.

16. Verteporfin therapy for subfoveal choroidal neovascularization in pathologic myopia: 3-years results of an open-label extension following completion of a 2-year randomized clinical trial-Vip report $\mathrm{N}^{\circ} 6$ (in press).

17. Rosenfeld PJ, Brown DM, Heier JS, et al. Ranibizumab for neovascular age-related macular degeneration. N Engl J Med 2006;355:1419 -31.

18. Ciulla TA, Rosenfeld PJ. Antivascular endothelial growth factor therapy for neovascular age-related macular degeneration. Curr Opin Ophthalmol. 2009 May;20(3):158-65.

19. McKay GJ, Silvestri G, Orr N, Chakravarthy U, at al. VEGF and age-related macular degeneration. Ophthalmology. 2009;116(6):1227.e1-3.

20. Chan WM, Lai TY, Chan KP, et al. Changes in aqueous vascular endothelial growth factor and pigment epithelial-derived factor levels following intravitreal bevacizumab injections for choroidal neovascularization secondary to age-related macular degeneration or pathologic myopia. Retina 2008;28(9):1308-13. 
21. Gunther JB, Altaweel MM. Bevacizumab (Avastin) for the treatment of ocular disease. Surv Ophthalmol. 2009;54(3):372-400.

22. Ruiz- Moreno JM, Montero JA. Subretinal fibrosis after photodynamic therapy in subfoveal choroidal neovascularization in highly myopic eyes. $\mathrm{Br} \mathrm{J}$ Ophthalmol 2003;87(7):856-9.

23. Grossniklaus HE, Gass JDM. Clinicopathologic correlation of surgically excised type 1 and type 2 submacular choroidal neovascular membranes. Am J Ophthalmol 1998;126:59-69.

24. Ergun E, Heinzl H, Stur M. Prognostic factors influencig visual outcome of photodynamic therapy for subfoveal choroidal neovascularization in pathologic myopia. Am J Ophthalmol 2004;138:434-8.

25. Fung AE, Lalwani GA, Rosenfeld PJ, et al. An optical coherence tomographyguided, variable dosing regimen with intravitreal ranibizumab (Lucentis) for neovascular age-related macular degeneration. Am J Ophthalmol 2007;143:566 83.

\section{FIGURE LEGEND}

Figure 1: results are presented as scatterplot of basal and final BCVA. Scatterplot presents the distribution of best-corrected visual acuity (BCVA) in logarithm of the minimum angle of resolution (logMAR) units before intravitreal injection and the final BCVA at the end of the follow up. The values below the red line show the eyes with a visual improvement; in addition, most of the remaining patients, even if not improving, show pretty stable visual acuity after the treatment (dots close to the red line).

Figure 2: demonstrative fluorescein angiography and OCT of three patients (indicated as 


\section{1, 2, 3).}

A1-3. middle/late phase FA before treatment, showing leakage from subfoveal neovascularization. B1-3. 12-14 months after treatment, showing resolution of leakage and peripheral annular window effect and central staining. C1-3. OCT scan before treatment showing intraretinal hyperreflective lesion, in case 2 and 3 associated with neurosensory detachment and/or intraretinal fluid. D1-3. OCT scan 12-15 months after beginning of treatment showing hyperreflective waveform changes of retinal pigment epithelium band associated with complete resolution of both the neurosensory detachment and intraretinal fluid. Arrow on images A indicates the OCT B-scan orientation. 


\section{Licence for Publication:}

The Corresponding Author has the right to grant on behalf of all authors and does grant on behalf of all authors, an exclusive licence (or non exclusive for government employees) on a worldwide basis to the BMJ Publishing Group Ltd and its Licensees to permit this article (if accepted) to be published in BJO editions and any other BMJPGL products to exploit all subsidiary rights, as set out in our licence (http://group.bmj.com/products/journals/instructions-forauthors/licence-forms/).

Competing Interest:

None to declare 


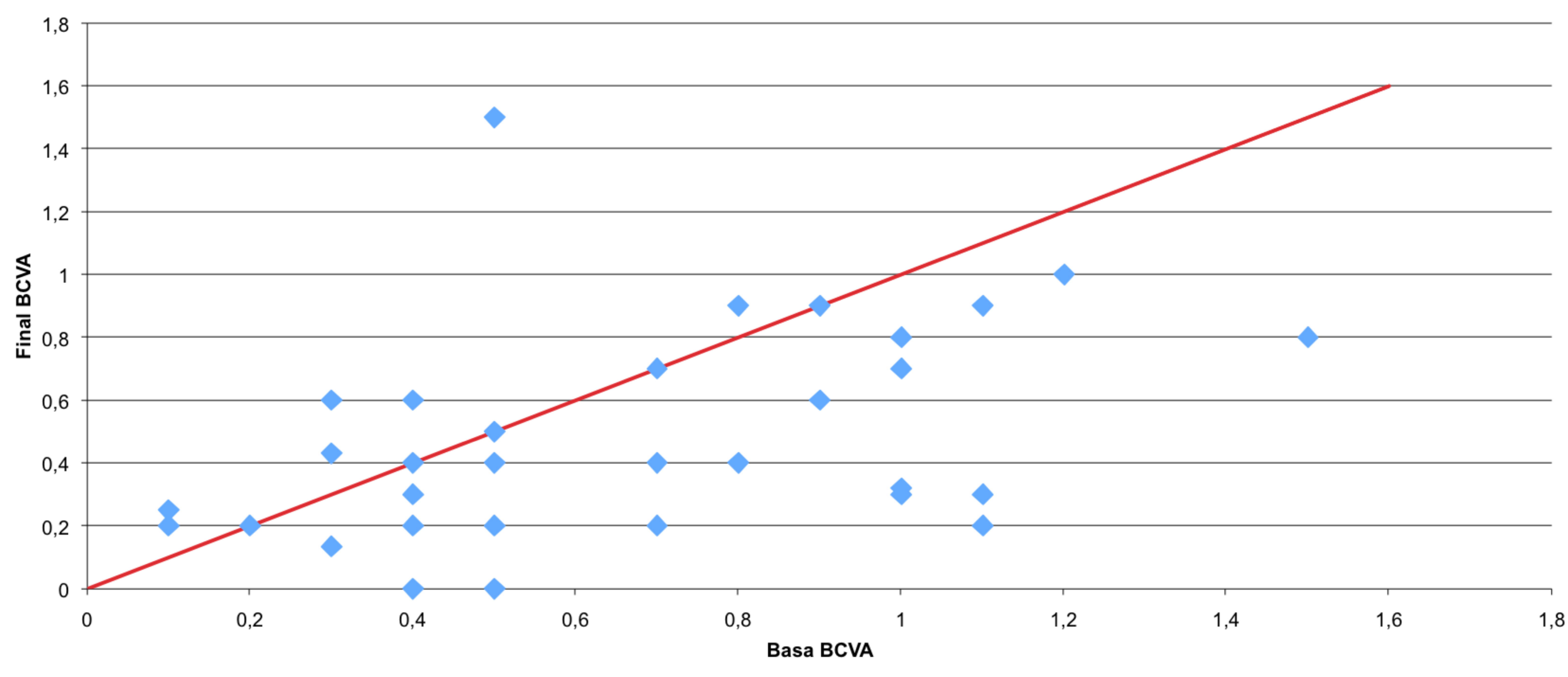




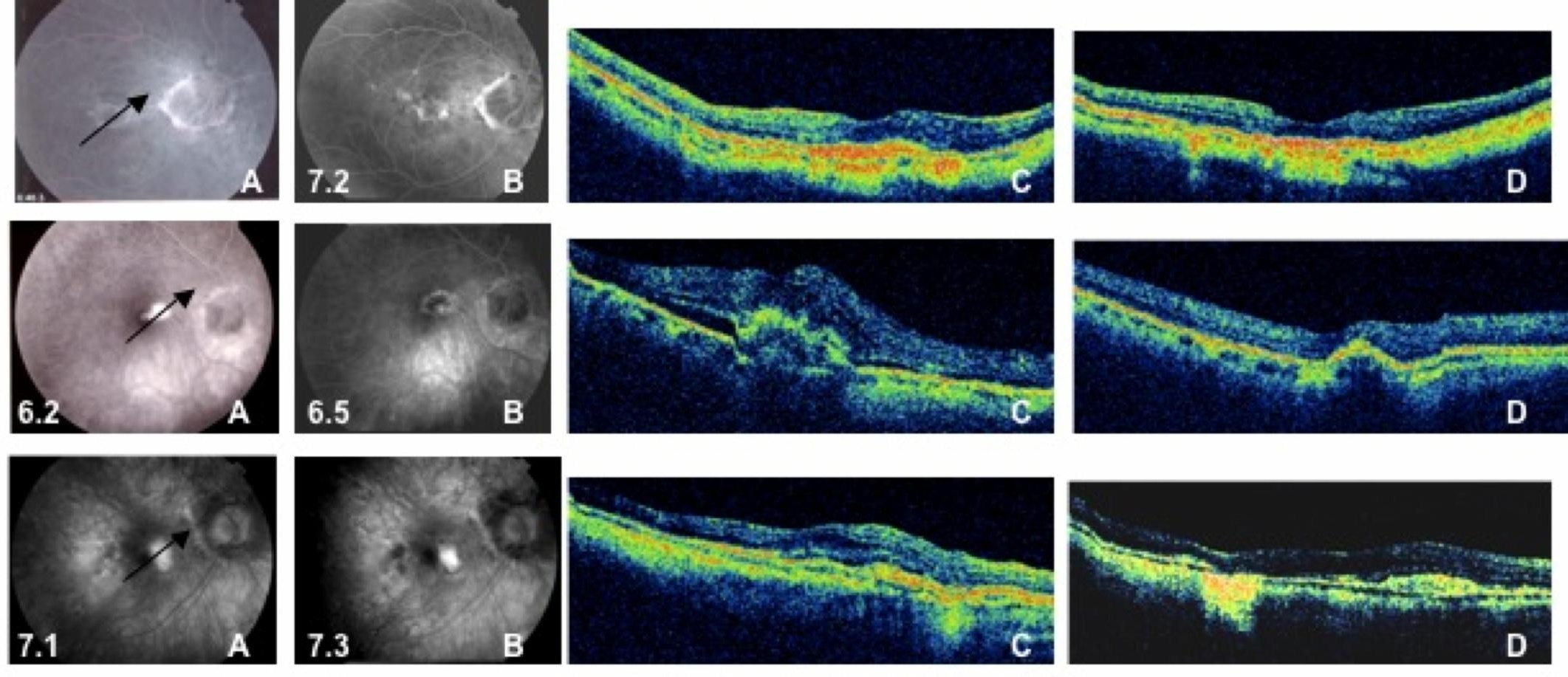

